\title{
Görsel Planlama Ve Pitoresk'i Yeniden Kurmak: Kentsel Tasarım Stüdyo Eğitiminde Kentsel Problemlere Yaklaşım
}

Yrd. Doç. Dr. Methiye Gül Çöteli

Makale Geliş Tarihi: 23.12.2016

Yayına Kabul Tarihi: 25.04.20I7

\section{Özet}

Şehir manzarası (townscape) stratejisi, yere duyarlı bir çerçeve oluşturmak ve mahalleyi çevresindeki konut alanlarına entegre etmektir. Esasen şehir manzarasının kökenini temsil eden pitoresk, yani tablomsu bir şehircilik tasavvuru günümüzde kentsel tasarım bağlamında yeniden yükselen bir yaklaşımdır. lyi tasarımın nitelikleri ve kentsel tasarımcının becerilerinin geliştirilmesi ise tasarım okullarındaki kentsel tasarım eğitiminden geçmektedir. Kentsel tasarımın önemine rağmen eğitimin öğrenciye kazandırdığı rol üzerinde yeterince tartışma yapılmamıştır. Bu makalede Erciyes Üniversitesi Mimarlık Lisans Programı'nda yürütülen kentsel tasarım stüdyo süreci ve yöntemi kent planlama, kentsel tasarım, görsel planlama ve pitoresk yaklaşımlar açısından ele alınmaktadır. Çalışmanın içeriği stüdyo eğitiminde çalışma alanı olarak belirlenen Incesu kentinin iç bölgelerinde takip edilebilecek kentsel tasarım stratejileri tavsiye etmeyi içermektedir. Stüdyo süreci sonunda stratejik danışmanlık ve geliştirmeye ilişkin olarak üretilen uygulanabilir ve gerçekleşebilir diyagramlar, gayrimenkullerin yeniden geliştirilmesi ve yapılı çevrenin tasarımı için bir çerçeve sağlamaktadır. Bunun yanı sıra araştırma mimarlık öğrencilerine tasarım eğitiminde kazandırılan rol üzerindeki bilgimizi genişletmektedir. Bu çalışmanın katkısı pitoresk şehircilik ile toplumsal şehirciliğin buluşturulması gerektiğini teyit etmek olmuştur.

Anahtar Kelimler: Kentsel Tasarım, Görsel Planlama, Kentsel Manzara Stratejisi, Pitoresk Şehircilik, Tasarım Eğitimi

\section{RECONSTRUCTING THE VISUAL PLANNING AND PICTURESQUE: AN APPROACH OF URBAN DESIGN EDUCATION TO URBAN PROBLEMS}

\section{Abstract}

The townscape strategy is to provide a framework sensitive to location, and integrate the neighbourhood into the back surrounding residential areas. In fact, a picturesque urbanism that represents the origin of the townscape is a re-emerging approach in the today's context of urban design. However, the development of good design qualities and skills of the urban designers meets in urban design education in design schools. Despite the importance of urban design, there has not been enough discussion on the role that education brings to student. This article depicts the urban design studio process and the method, conducted in Erciyes University undergraduate architectural program, in terms of urban planning, urban design, and visual planning and picturesque approaches. The context of the study comprises suggesting pursuable design strategies proposed for the inner areas of Incesu, in Kayseri, which is determined as a study area for design studio education. At the end of the process, applicable and realizable diagrams, involved in advising and devising strategies, provide a framework for the redevelopment of the estates and design of the built environment. In addition to this, the research extends our knowledge of role gained by the architecture students through design education. The contribution of this study has been to confirm that it is necessary to bring together the picturesque urbanism with the social urbanism.

Keywords: Urban Design, Visual Planning, Townscape Strategy, Picturesque Urbanism, Design Education

Yrd. Doç. Dr. Methiye Gül Çöteli, Bursa Teknik Üniversitesi, Doğa Bilimleri, Mimarlık ve Mühendislik

Fakültesi, Şehir ve Bölge Planlama Bölümü, Bursa

E-posta: methiye.coteli@btu.edu.tr, arctyler@gmail.com 


\section{Giriş: Kentsel Tasarımın Dünü Ve Bugünü}

Kentsel tasarımın kuramsal temellerine bakıldığında pek çok ileri gelen arasında Gordon Cullen'in (1961) "bir bina mimarlıktır ama iki bina kent peyzajıdır (townscape)" ifadesi çok çarpıcı bir biçimde kentsel tasarımı görünüm, manzara ve sanat ile ilişkilendirmektedir. Hâlbuki, onun öncesinde townscape hareketinin ilk yaratıcısı olan Nikolaus Pevsner 1940'lı yıllarda şehir manzarasının kökenini 18. yüzyılın "pitoresk" ${ }^{1}$ fikrine dayandırırken ${ }^{2}$ planlamanın, kentin genel kompozisyonuna resimsel bir gözle yaklaşarak görsel olarak yapılması gerektiği konusunda çağrıda bulunur (Aitchison: 2010). Bir başka ifade ile Pevsner kütleler, mahalleler ve şehir silueti yapımında eski ile yeniyi, ulusal ile uluslararası olanı yan yana koyan kompozisyonların bütüncül bir şekilde oluşturulmasını ister ${ }^{3}$.

Günümüzde ise çok boyutlu, çok ölçekli, interdisipliner bir yaklaşım olarak yapı gruplarına görsel, form ve biçim vermek suretiyle bir "yer yaratma (place-making)", tanımsız ve/veya köhnemiş bir alana yer duygusu kazandırma eylemi olan kentsel tasarım bir süreç olarak tarif edilir ${ }^{4}$. Bu sürecin şekillenmesi bilhassa kent planlama, mimarlık ve peyzaj mimarlığı arakesitinde meydana gelmektedir. Kentsel tasarımın esasen en temel rolü kentsel alanları daha işlevsel ve çekici hale getirmektir. Avrupa'nın Berlin, Manchester, Prag, Barselona, Bilbao gibi pek çok şehrinde mimarlık, kentsel tasarım, planlama, altyapı geliştirme ve ekonomik kalkınma birbiri içerisine geçerek bir kent yaratma biçimi haline dönüşmüştür (Russell: 2005). Rowe ve Koetter'ın (1978) "Kolaj Kent" çalışmasının vurguladığı eski ve yeni, şimdiki ve geçmiş arasında bir uyum önerisi kentsel tasarım yaklaşımlarının hiç kaybetmediği bir önermedir. Bunun içeriği ağırlıklı olarak fiziksel ve biçimsel bir yön verme hassasiyeti taşımaktadır. Ancak kent ve onun her bir parçası fiziksel olduğu kadar aynı zamanda hem sosyal ve kültürel, hem ekonomik bir varlıktır. Dolayısıyla kent planlama ve kentsel tasarım arasındaki çekişmeli durum güzel olan mı yoksa iyi olan mı sorusunu zihinlerimize yükler.

Şu bir gerçek ki, kalitesiz, baştan savma, ikinci sınıf bile olamayacak kadar

\footnotetext{
I Pitoresk sözcüğ̈̈ Türkçe’ye anlamı "resimsi”, “durumu ve görünüşü resim konusu olmaya değer (görünüş)” olarak uyarlanmış Fransızca "pittoresque” kelimesinden geçmiştir. Internet: Türk Dil Kurumu. http://www.tdk.gov.tr/index.php?option=com gts\&arama=gts\&guid=TDK. GTS.590 lald84f7252.7660278I 27 Nisan 2017'de alınmıştır.

2 Internet: An Interview with Mathew Aitchison, https://getty.edu/research/publications/pevsner/ index.html I7 Mart 2016'da alınmıştır.

3 İnternet: Hicks, J. (July, 20I I). Painterly Urban Planning: NikolausPevsner's "Visual Planning andthePicturesque". http://blogs.getty.edu/iris/painterly-urban-planning-nikolaus-pevsners-visual-planning-and-the-picturesque/ adresinden 17 Mart 20 I6'da alınmıştır.

${ }^{4}$ İnternet: The Art of Creating and Shaping Cities and towns, http://www.urbandesign.org/home. html 20 Mart 2016'da alınmıştır.
} 
kötü yapılara; yaratıcılıktan yoksun mimarlığa; kentsel dış mekânlara tahammül etmek zorunda olmadığımız iddia edilebilir. Bunun tam tersi bir yaklaşımla Zaha Hadid "kentlerin birçok kez görülen korkunç ucuz bir binayı yapmaktan daha fazla etkiye sahip olan iyi mekânsal düzenlemelere yatırım yapması gerektiğini" ifade eder. Doğrusu hem yapılar arasında kalan boşlukların hem bu boşluğu meydana getiren yapıların bir bütünü, yani kenti oluşturması nedeniyle her ikisinin de iyi düzenlenmesi bir ihtiyaç, kent sakinlerinin talep etmesi gereken bir haktır.

Kent planları gelişmenin kontrolünü ve yönlendirilmesini sağlayan bir temel ortaya koyarken plan sınırı içerisinde tasarıma genel bir çerçeve hazırlamaktadır. Bu bağlamda iyi planlamanın başlıca hareket noktası, gerçekleşmesi güvence altına alınmış iyi tasarımdır (CABE, 2000: 9). Bu sebeple kentsel gelişme planlarının alan, yer odaklı ve konu esaslı olmak üzere üç farklı kategoride tasarım politikaları içermesi ve bu planlarda hatta kentsel tasarım uygulamaları için alanların tespit edilmesi beklenmektedir (CABE, 2000: 45). Alan odaklı politikalar tasarım alanına belirgin bir karakter vermede yardımcı olacak alanlar; eski kent merkezleri, koruma/sit alanları, su kıyıları, rıhtımlar, ulaşım koridorları, yenileme/dönüşüm alanları, kentsel saçak alanları gibi belirgin bir karakter ya da kullanıma sahip olan alanlar için geliştirilir. Kentsel gelişme planlarında alan odaklı politikalar bu alanlar için kentsel tasarım çerçevesini hazırlamada maksadı açıkça izah etmelidir. Ayrıca kentsel tasarım amaçlarından en önemlileri olan erişim kolaylığı, kamusal alanların kalitesi, süreklilik ve kapalılık üzerine özen gösterilmelidir (CABE, 2000: 45-46).

Daha iyi tasarımlar için koşulları yaratan planlama sistemini etkili bir biçimde kullanmak pozitif yönetim, anlamlı işbirliği ve sağlam beceriler gerektirir (CABE, 2000: 9). Planlamanın içeriğinde bulunan ve aslında bir olumsuz mana taşıyan standartlara olan güvenden daha olumlu bir anlam ifade edecek olan performans kriterlerine olan vurguyu güçlendirmesi gerekmektedir. Bir başka ifade ile standartlar artık daha iyi bir tasarımın koşulu olamamaktadır. Bunun yerine belirli planlama gereksinimlerini gidermenin ölçüsünü tayin etmek önemlidir. Her ne kadar tasarımcının becerileri burada belirleyici ise de, yaratıcı tasarımcılar önerdikleri tasarım çözümleri ile performans kriterlerine yanıt verebilir (CABE, 2000: 9-10).

Bu nedenle günümüzde görsel planlamada pitoresk, tablomsu bir şehircilik tasavvuru kentsel tasarım bağlamında yeniden yükselen bir yaklaşımdır. Bununla birlikte kentsel tasarımcının rolü artık yalnızca iyi bir tasarım

\footnotetext{
5 Internet: Smith, C. S. (2015, February 25th). Interview with Zaha Hadid, 'Zaha Hadid At The Royal Academy Of Arts'. Royal Academicians' Room, The Royal Academy of Arts, London http://alainelkanninterviews.com/zaha-hadid-ra/ adresinden 27 Mart 2016'da alınmıştır.
} 
yapmakla yetinemeyecek kadar çoğalmıştır. Giannopoulou (2014: 18-19) kişilik özellikleri, deneyimler ve beceriler dizisine bağlı olarak tasarımın yeni yönlerinin ayrıştırdığı kentsel tasarımcıların yükselen rollerini beş farklı başlık altında toplamaktadır. Bunlar:

- Vizyoner yatırım danışmanı olarak kentsel tasarımcı,

- Proje başlatıcısı \& özet kurucu olarak kentsel tasarımcı,

- Tasarım ekibi yöneticisi olarak kentsel tasarımcı,

- Avukat olarak kentsel tasarımcı,

- Müzakereci olarak kentsel tasarımcıdır.

Bu bağlamda kentsel tasarımın mahiyeti, iyi tasarımın nitelikleri ve tasarımcının becerilerinin geliştirilmesi tasarım okullarındaki kentsel tasarım eğitiminden geçmektedir. Planlama, mimarlık ve tasarım okullarındaki eğitimin en önemli parçalarından biri lisans müfredatında yer alan kentsel tasarım dersleridir. Ders kapsamında kentsel tasarım sürecinin nasıl ele alınacağı uygulamalı olarak izah edilirken, tasarımcının rolü ve işlevi hakkında bilgi sunulmaktadır. Mimarlık okullarında yürütülen kentsel tasarım derslerinde üst ölçekli plan kararları ve politikaları saptanmadan gerçekleştirilen uygulamanın sonuçları kentsel tasarımdan çok mimarlık ve yapı tasarımına odaklanmaktadır. Bir başka ifade ile kentsel tasarımı özündeki interdisipliner olmanın verdiği bir zemine taşımakta zorlanılmaktadır. Bu nedenle planlama ve kentsel tasarım arasındaki çelişkinin bertarafı adına öncelikle tasarım eğitimindeki stüdyo uygulamaları can alıcı bir konumdadır. Dolayısıyla bu çalışmada Erciyes Üniversitesi Mimarlık Bölümü lisans programında, 2015 bahar yarıyılında yürütülen Kentsel Tasarım stüdyo süreci ve yöntemini şehir planlama, kentsel tasarım, görsel planlama ve pitoresk yaklaşımlar üzerinden yeniden ele almak ve kentsel tasarımda öğrenciye kazandııılan rol üzerine değerlendirme yapmak amaçlanmaktadır. Diğer yandan çalışma stüdyo eğitimi için belirlenen İncesu kentinde takip edilebilecek kentsel tasarım stratejilerini tavsiye etmeyi ve planlamayı, bir başka ifadeyle yerleşme için vizyoner yatııı danışmanlığı yapmayı kapsamaktadır. Böylece tasarım eğitimine ilişkin getirilen yeni yaklaşım ortaya konulacak ve kentsel tasarım ile planlama arasındaki adaptasyon ve geçirgenlik örnek projeler üzerinden sergilenecektir. Bu noktada çalışmanın ikinci bölümünde stüdyo proje alanının temel özellikleri açıklanmaktadır. Üçüncü bölümde kentsel tasarım eğitiminde kullanılan proje yapım süreci ve yöntemi açıklanmaktadır. Bununla birlikte süreç içerisinde geliştirilen konsept tasarımları ve sonuç ürünler izah edilecektir. Çalışmanın son bölü- 
münde ise projeler üzerinden eğitim sürecinin değerlendirmesi yapılmakta ve öğrenciye kazandırılan tasarımcı rolü tartışılmaktadır.

\section{2. İncesu'nun Kayseri Metropoliten Alan İçindeki Stratejik Önemi}

2007 yılından bu yana metropoliten alan sınırı dâhilinde olan İncesu ilçesi, 2015 yılı verilerine ${ }^{6}$ göre 24.309 kişilik toplam nüfusu ile 1,3 milyonu aşkın nüfusa sahip olan Kayseri metropoliten kentinin 7. büyük ilçe merkezidir (Görsel 1). 17. yüzyıl Osmanlı dönemi Anadolu coğrafyasının önemli menzil külliyelerinden biri olan Merzifonlu Kara Mustafa Paşa ${ }^{7}$ külliyesinin cami, kervansaray, arasta, medrese, sibyân mektebi, çeşme, fırın ve suyolları sayesinde arazi şenlendirilmiş ve insanların buraya yerleşmesi teşvik edilmiştir.

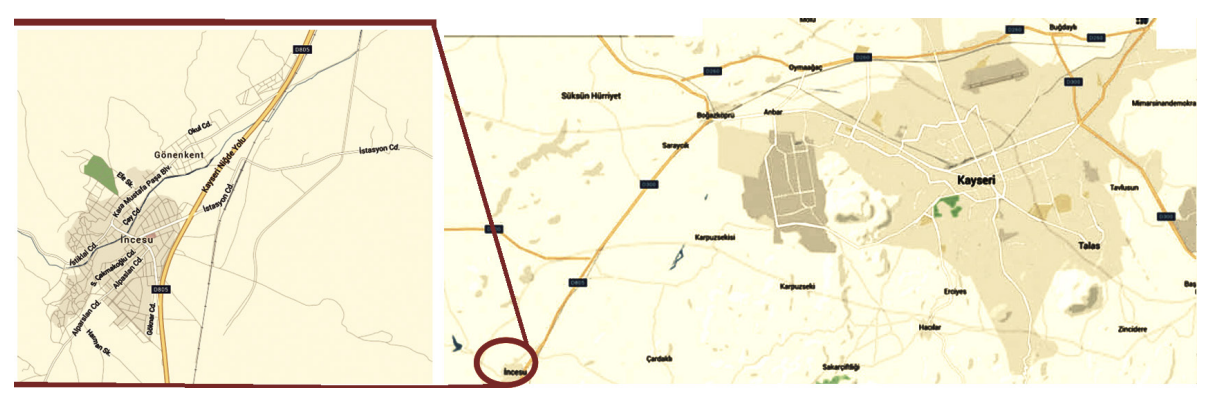

Görsel I. Metropoliten Alan Içerisinde Incesu Kenti ${ }^{9}$

Tarihi İpek yolu güzergâhı üzerinde bulunan yerleşmenin ilk nüvesi kısa zaman içinde civar köylerden gelen nüfusun yerleşmesi neticesinde 6 Rum ve 5 Türk mahallesinden teşekkül etmiştir (Sarı ve Karababa: 2005). Böylece 21. yüzyılın İncesu kent merkezi kuzey-güneydoğu akış yönlü İncesu deresinin yönlendirdiği dar ve uzun vadinin doğu istikametine doğru genişlediği yamaçlarda kurulmuştur. Seyahatnamelerde yerleşmenin şaraplarının güzelliğinden bahsedilirken (Tozer: 1881) günümüzde halen üzüm yetiştiriciliği konusunda ilçenin bölge içinde ayrıcalıklı bir yeri vardır.

\footnotetext{
${ }^{6}$ Internet: TÜIK. (20I5). Adrese Dayalı Nüfus Kayıt Sistemi Sonuçları, https://biruni.tuik.gov.tr/medas/ adresinden 20 Mart 2016'da alınmıştır.

${ }^{7}$ Merzifonlu Kara Mustafa Paşa, IV. Mehmet Sultan döneminin sadrazamlarındandır.

${ }^{8}$ İlçenin önemli tarihi eserleri arasında Merzifonlu Kara Mustafa Paşa Külliyesi, Merzifonlu Kara Mustafa Paşa Câmii, Merzifonlu Kara Mustafa Paşa Medresesi, Merzifonlu Kara Mustafa Paşa Hamamı, Bulgurcu Câmii, Karakoyunlu Câmii, Yeni Câmi, Osmanoğlu Çeşmesi, Şeyh Turesan Zâviyesi, Agios Dimitrios Kilisesi ve Agios Efstatios Kilisesi bulunmaktadır.

9 Internet: Incesu haritası, https://www.google.com.tr/maps/@38.626499I,35. I80044, I4z I3 Mart

2016'da alınmıştır.
} 


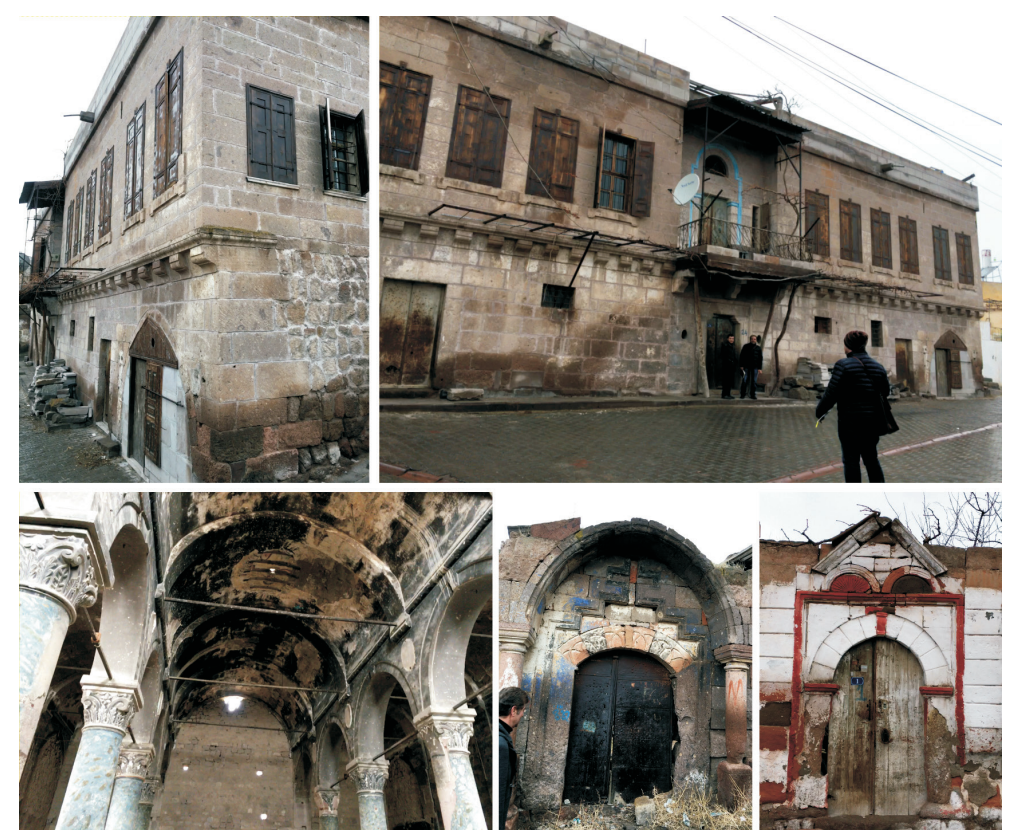

Görsel 2. Yerleşmenin Özgün Mimarisi

Yerleşme yalnızca tarihi, kültürel ve doğal değerleri ile değil aynı zamanda son on yıl içinde İncesu Organize Sanayi Bölgesi, TOKi konutları, MEB İncesu Eğitim Kampüsü, ERÜ İncesu Meslek Yüksekokulu gibi önemli kamu yatırım kararlarının merkezi olması ile adını metropoliten kent içinde öne çıkarmıştır. Ne var ki, kentsel sit alanında yer alan geleneksel sivil mimarlık örnekleri ile arasta, cami ve kiliseler gibi bazı anıtsal yapıların korunması konusunda yaşanan sıkıntılar ile yerleşmenin yerel nüfusunun kaybedilmesi sonucunda geleneksel konut dokusu büyük oranda boşalmıştır (Görsel 2). Son on yıl içinde terkedilen konutların bir bölümü doğu ve güneydoğudan gelen göçmenlerce kullanılır hale gelmiştir. Buna rağmen, yerleşmenin harabe ve terkedilmiş görüntüsünün önüne geçilememiş ve dolayısıyla mekânsal sorunlar beraberinde sosyolojik sorunları ortaya çıkarmıştır. Bu nedenle İncesu ilçesi Kayseri metropoliten alanında acil olarak çözülmeyi bekleyen fiziksel, sosyo-kültürel ve ekonomik problemlerin iç içe geçtiği bir bölge olarak tezahür etmektedir.

\section{Kentsel Tasarım Proje Süreci Ve Yöntem}

Kentsel Tasarım stüdyosunda öğrencilerin kentsel tasarım sürecini deneyimlemeleri için bir sorun odağı haline gelen İncesu ilçesi proje alanı olarak seçilmiştir. Projenin genel hedefi gelecek kuşakların ihtiyaçları doğrultusunda şehrin yeniden biçimlendirilmesi için mevcut ve eski kent 
dokusu katmanlarını eleştirel bir gözle tanımlamak, tespit edilecek öncelikli sorun alanları için araştırmalar ve çözüm yolları geliştirmektir. Süreç içinde öğrencilerin maksimum düzeyde özgür hareket edebilmeleri istenmiştir. Bunun için alana özgü ve öncelikli olarak belirlenen problemler üzerinden çalışma alan sınırı ve büyüklüğünün tayini ile bağlamın tanımlanması öğrencilerin öngörüsüne bırakılmıştır.

Yarıyıl boyunca öğrencilere kentsel tasarım süreci, çalışma alanının tanımlanması, alan analizi, konsept tasarımı ve tasarım stratejileri hakkında teorik bilgiler içeren seminerler düzenlenmiştir. Böylece öğrencilerin tasarım çalışmalarına yön kazandırması beklenen kuramsal bir altyapı hazırlanmıştır. Bunun yanı sıra stüdyo çalışmalarında üç genel aşama takip edilmiştir. Bunlar: 1. Aşama: alan analizi, 2. Aşama: tasarım konsepti, sentez, etki ve senaryo, 3. Aşama: tasarım önerisidir (Görsel 3).

Birinci aşamada kentsel tasarım sürecinin bir ekip çalışması olması sebebiyle 72 kişiden oluşan stüdyo öğrencilerinden 6 kişilik toplam 12 grup oluşturulmuştur. Grupların belirledikleri çalışma alanı ve probleme kendi tasarım yaklaşımlarını geliştirmeleri beklenmiştir. Bunun için pek çok farklı kaynaktan bilgilerin toplanması, alanda gözlem ve incelemelerin yapılması neticesinde değerlendirmeye gidilmiştir. Böylece her grubun çalışma alanı ile ilgili arazi, jeoloji, su, sürdürülebilirlik, konut, kültür, ulaşım, altyapı konu başlıklarında bilgi katmanlarını oluşturmaları ve bunları fiziksel ve mekânsal grafikler ile ifade etmeleri gerekmiştir. Karar verme sürecini şekillendirmede alanın mekânsal, ekonomik, sosyal ve çevresel özelliklerine işaret eden bir SWOT analizi ile araştırmaların desteklenmesi istenilmiştir. Tüm bu çalışmaların fotoğraf, $2 \mathrm{~d}$ ve $3 \mathrm{~d}$ modellemeler ile diyagramlar, haritalar, alanda kaydedilmiş ses dosyaları ve serbest el eskizleri gibi diğer destek malzemeleri içeren bir biçimde dijital formatta hazırlanmış olmasına dikkat edilmiştir.

İkinci aşamada öğrencilerin belirlenen temel meselelere ilişkin koşulları vurgulayarak alana ilişkin net bir tasarım konsepti tanımlamaları beklenmiştir. Her grubun kendi çalışma alanı için kapsamlı bir tasarım önerisi üretmesi; önceki çalışmalarda toplanan bilgilerin düzenlenmesi, yeniden değerlendirilmesi ve ilişkilendirilmesi sonucunda ortaya konulmuştur. Her bir grubun tasarım önerisi 3 temel konuyu içerecek şekilde geliştirilmiştir. Bunlar konsept, sentez ve etkidir. Sentez içeriğinde tasarım önerisinin kentin genel dokusu içinde kendini nasıl yerleştireceği, bağlamsal karar yönteminin ne olduğu ve yerel, bölgesel ve muhtemelen küresel ölçekte yeni ilişkiler oluşturmak için hangi potansiyellerin var olduğu soruları üzerinden sorgulama yapıımıştır. Her grup çalışma alanında ortaya çıkması 
tahmin edilen yeni etkiyi yani tasarım önerisinin alan dinamiklerini nasıl değiştirebileceğini açıkça göstermekle sorumlu kılınmıştır.

Üçüncü aşamada her bir grup makro ölçekte ortaya koydukları tasarım stratejilerinin mikro ölçekte yaratacağı mekânsal çevreyi tasarlamıştır. Öğrenciler çalışma alanları için bir kentsel tasarım önerisi geliştirmiş, özgün alan analizi yanı sıra kentin geleceği için geliştirilen hipotezlere dayanan, şehir ölçeğinden mahalle ölçeğine kadar kenti dönüştürme potansiyeline sahip uygulama stratejilerini ele almıştır. Bu aşamanın gerçekleştirilmesinde fiziksel ve dijital modellemeler, tüm destekleyici araştırma materyalleri ve mimari ölçekte çizimler (plan, kesit, diyagram, perspektif, vb.) kullanılmıştır. Böylece öğrencilerin gruplar halinde çeşitli ölçeklerde (1/25.000, 1/5000, $1 / 1000$ ve 1/500) çalışarak çok katmanlı bağlamı tanımlamaları istenmiştir. Aynı zamanda alan araştırma teknikleri hem fiziksel hem fiziksel olmayan düzlemde; coğrafi, tarihsel ya da sosyo-ekonomik nitelikleri, yerleşmeler sistemini, etkileşim ve etki ağlarını içeren bir biçimde geliştirilmiştir. Bu bağlamda kentsel planlama ve tasarım ilişkisinin kurulması önemli olmuştur.

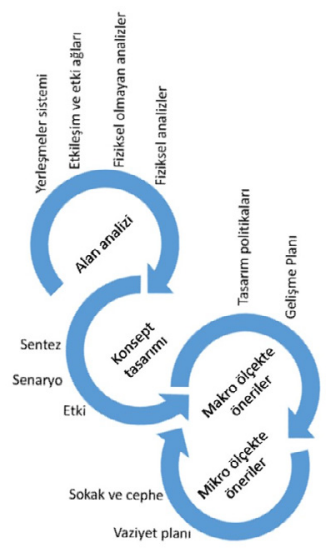

\section{Görsel 3. Bulvar Proje Onerisinden Detaylar}

Sonuçta, öğrenciler kendi problem alanlarını ve tasarım programlarını kent planları ile ilişkilendirerek oluşturmuşlar ve tasarım alanı için çeşitli ölçeklerde ve farklı ebatlarda öneriler getirmişlerdir. Alan araştırmalarında yapılan sorgulamalar neticesinde geliştirilmesi beklenen temalar, çözüme kavuşturulması istenen meseleler ile ilişkili olarak 12 farklı konsept tanımlanmışır. 


\subsection{Bulvar ${ }^{10}$}

Atatürk Bulvarı yerleşmeyi Kayseri, Niğde ve Nevşehir'e bağladığı gibi eski ve yeni kent dokusu arasında kalmış bir sınır elemanıdır. Bulvar; iki ucunda bulunan araç ve yaya düğüm noktaları sayesinde, kentsel imajın önemli bir parçasını teşkil etmektedir. Öğrenciler cadde üzerindeki alan kullanımlarını analiz ederek dolaşım ve sokak ağı içerisinde bulvarın önemli bir arter olduğunu vurgulamışlardır. Öğrencilerin çalışmaları, yapılar arası açık alanların geniş olması, siluette yapı gabarileri arasındaki düzensizlik ve uyumsuzluk, bulvarın süreklilik dengesinin kesintiye uğradığını ortaya koymuştur. Bu nedenlerle doluluk etkisini güçlendirerek sürekliliği sağlayıcı bir örtü sistemi ve yapı düzenlemeleri (infill) önerilmiştir (Görsel 4).

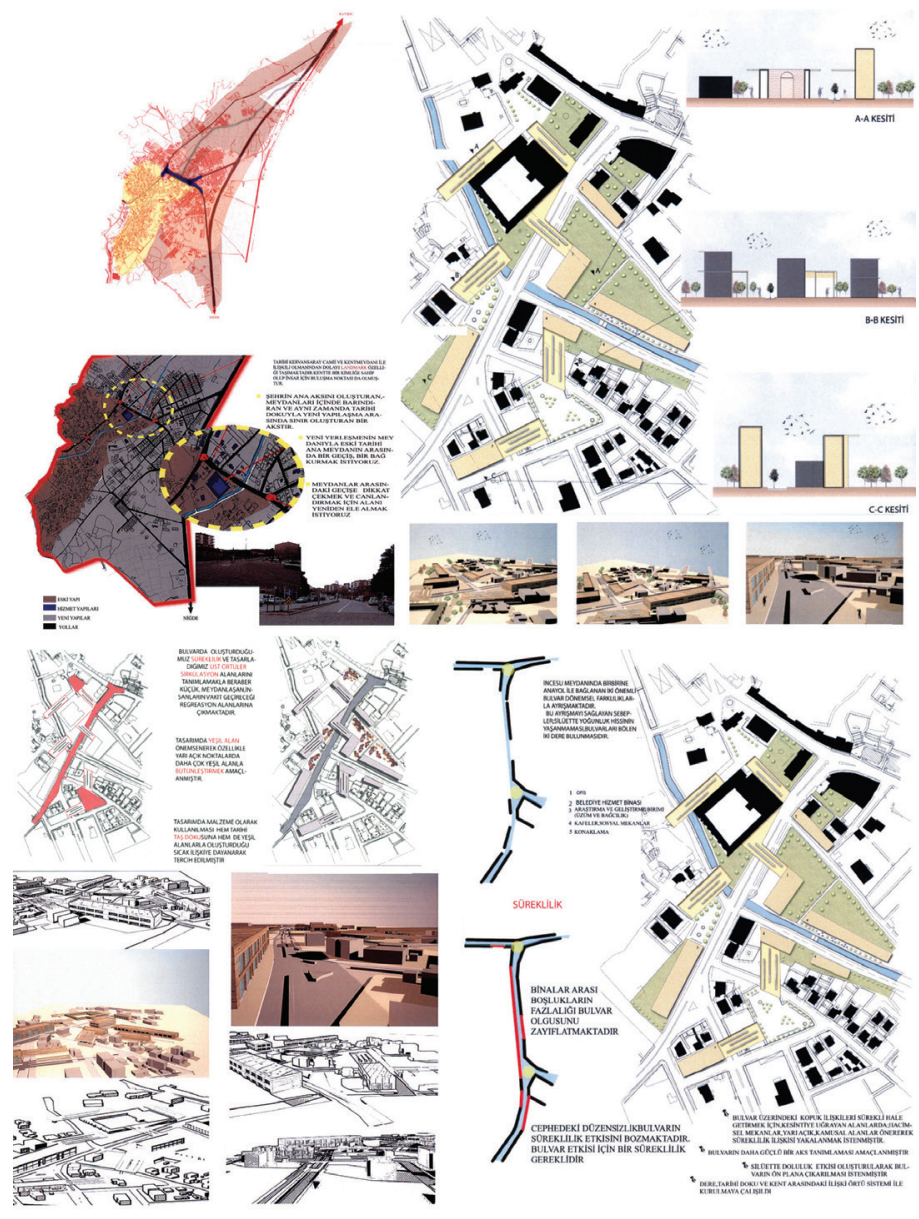

Görsel 4. Bulvar Proje Önerisinden Detaylar

\footnotetext{
${ }^{10}$ Bu proje önerisi Dilek Polattaş, Feray Aluçlu, Sema Balçık, Gamze Bağcı, Eda Demiryürek, Ayşe Demirel tarafindan geliştirilmiştir.
} 


\section{2 Çocuk Esirgeme Kurumu ve Güzel Sanatlar Eğitim Kampüsü11}

Kamusal mekânları eğitim açısından değerlendiren öğrenciler İncesu'nun toplam nüfusunun eğitim durumunun, benzer nüfusa sahip diğer ilçeler ile karşılaştırdığında yerleşmenin öne çıktığını ifade etmiştir. Araştırma raporunda üniversite eğitimi almış nüfusun ortalamanın üzerinde olduğu belgelenmiştir. Dolayısıyla eğitim yapıları ile öğrenci yurtları ve konut alanlarını içeren bir bölge proje alanı ${ }^{12}$ için öncelikli olmuştur. Ayrıca çocuk esirgeme kurumunda yetiştirilen çocukların sanat ve spor ile iç içe vakit geçirerek topluma kazandırılması fikri benimsenmiştir.

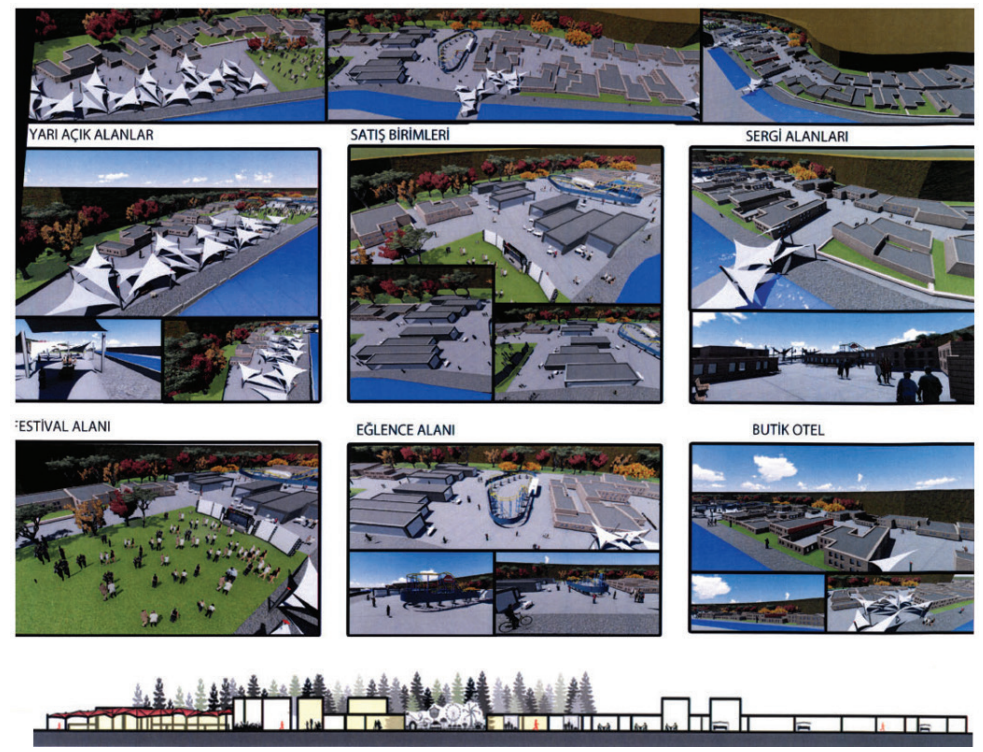

Görsel 5. Festival Proje Önerisinden Modellemeler

\subsection{Festival dé İncesu ${ }^{13}$}

İncesu kent merkezinde İncesu belediyesi tarafından her yıl Ekim ayında düzenli olarak gerçekleştirilen "Üzüm Festivali" ile Ramazan ayı etkinlikleri için kent merkezinin güneyinde bulunan park alanı kullanılmaktadır. Alan peyzaj uygulamaları olmasına karşın söz konusu etkinlikler dışında nadiren kullanılmaktadır. Bu nedenle öğrenciler alanın yalnızca festival zamanı değil aynı zamanda ticaret, turizm ve küçük el sanatlarından oluşan bir ticaret

\footnotetext{
${ }^{12}$ Alanın 6- 8 yaş grubu öğrencilere yönelik (ilk, orta ve lise düzeyinde eğitim yapıları, öğrenci yurtları ve lojmanlar bulunan) bir eğitim kampüsü niteliğinde çocuk esirgeme kurumu ile güzel sanatlar okulunun birlikte tasarlanması önerilmiştir.

${ }^{13}$ Bu proje önerisi Hatice Özler, Hilal Hardal, Ebru Nur Baysar, Hayrunnisa Kırılmaz, Hüsne Kayış, Ayşe Taş tarafindan geliştirilmiştir.
} 
ve çalışma alanı olarak tasarlanması aracılı̆̆ıyla yerleşmenin geleneksel zanaatlarının yaşatımasını, ekonomik yatırımların geliştirilmesini önermiştir (Görsel 5).

\subsection{Geçiş}

İncesu deresinin kuzeyinde kalan alanın güneydoğu ve kuzeydoğusunda yoğun konut dokusu bulunmaktadır. Ancak geleneksel az katlı konut tipolojisi ile modern çok katlı konut tipolojileri arasında ekili tarım arazileri mevcuttur. Dokular arasındaki bu radikal, keskin ve sert geçişi yumuşatacak bir tampon bölgenin planlanması düşünülmüştür. Bu nedenle projede ara katlarda bahçe ve iç avlu düzenlemeleri kurgulanmış, böylece hem açık alanlarda hem kütleler arası yüksekliklerde denge ön plana çıkarılmıştır.

\subsection{Ignimbrite ${ }^{14}$}

Yerleşmenin jeolojik ve topografya özellikleri nedeniyle Kapadokya bölgesindeki kaya oluşumlarına ${ }^{15}$ benzer olması dikkat çekicidir. Bu nedenle merkezde bulunan kayalık bölge için öğrenciler tarafından bir kentsel tasarım önerisi geliştirilmiştir. Incesu meydanından yaklaşık 18m kadar yükselen kayalık alanının merkezi bir noktada panoramik manzaraya olanak vermesi önemli bir fırsat olarak tanımlanmıştır. Bunu geliştirmek amacıyla karma kullanımlar ile işlevsel çeşitlilik yaratmak ve bunlar arasındaki yaya dolaşımını rampalar ile sağlamak istenmiştir (Görsel 6).

\section{$3.6 \operatorname{Kadın}^{16}$}

Kamusal kullanımlarvemekânsal cinsiyete odaklananöğrencileryerleşmede sosyo-kültürel faaliyetlerin yetersiz olduğunu, özellikle nüfusun $1 / 2$ 'sini oluşturan kadınların kamusal alanlarda görünürlüğünün düşük olduğunu belgelemişlerdir. Bu nedenle konut bölgeleri ile kamusal mekânları, landmarkları bütünleştirmek ve kültürel etkinlikleri toplumun tamamına yaymak hedeflenmiştir. Yerleşmenin öne çıkan landmark'larından biri olan Merzifonlu Kara Mustafa Paşa Kervansarayının kapalı avlulu yapı formu transformasyona uğratılarak yeni yapı tasarımında kullanılmıştır.

\footnotetext{
${ }^{14}$ Bu proje önerisi Çağrı Daşan, İrem Akdağ, Jale Şahin, Zehra Özlük, Fatma Erkan, Gülsüm Özata, Hacer Yuvayapan tarafindan geliştirilmiştir.

15 Bunlar bölgede görülen piroklastik kayaçlar grubunun bir çeşidi olmakla birlikte jeolojik bir terim olan "Ignimbrite" adı ile anılmaktadır. (Bkz. Koralay, Zoroğlu ve Kadığlu,2009)

${ }^{16}$ Bu proje önerisi Hürmet Çoğuroğlu, Zehra Aksoy, Başak Elbaş, Beyza Büyüknalbant, Merva Hasözhan, Rukiye Boran geliştirilmiştir.
} 


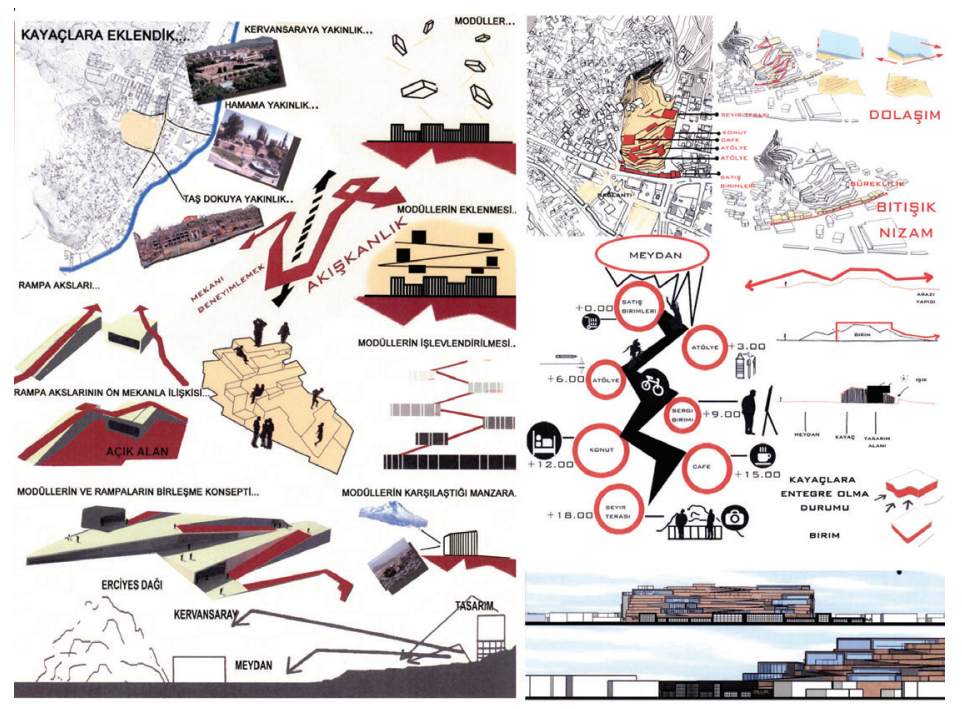

Görsel 6. İgnimbrite Proje Önerisinden Konsept Diyagramları

\subsection{Komşuluk Ünitesi}

Geleneksel konut alanlarına özgü mahalle kavramı ile Clarence Perry'nin "komşuluk ünitesi" yaklaşımını tartışan öğrenciler İncesu deresinin güneybatısındaki üç ardışık meydanı içine alan konut bölgesini proje alanı olarak belirlemiştir. Burada bir yandan geleneksel mahalle yaklaşımını, sokak-yaya ilişkisini canlandırma, diğer yandan modern konut ilaveleri ile boş olan parsellerde yapılaşma önerisi getirilmiştir.

\subsection{Organik Yaşam Durağı}

Analizler yerleşmenin halen temel ekonomik sektörünün tarım ve hayvancılık olduğunu ortaya koymuştur. Yerleşmede yöresel gıda üreticilerinin, çiftçilerin Cuma günleri pazar kurması öğrencilerin kentsel tarım ile organik yaşamı birleştirme yönündeki fikirlerine cesaret vermiştir. Bu nedenle tohum-tarla-ürün-yemek dörtlemesi ekseninde organik üretim, beslenme, doğayla etkileşime açık, tarım ve hayvancılı̆̆a dayalı bir üretim içeren bir yapılı çevre tasarımı öne çıkmıştır.

\subsection{Katman $^{17}$}

Kentsel sit alanının güneybatısında sırtını kayalıklara yaslamış olan konut bölgesinin barınma işlevi ile kullanılmasına rağmen bölgede sosyal donatı

\footnotetext{
${ }^{17}$ Bu proje önerisi Merve Başhoroz, Emine Yıldırım, Hümeyra Dursun, Burcu Ulutürk, Abdullah Çam, Mustafa Taşan tarafindan geliştirilmiştir.
} 
alanı ihtiyacı olduğu belirlenmiştir. Bu nedenle farklı donatıları bölge içinde dağıtarak her bir katmanda işlevsel çeşitliliğin yaratılması, sosyal donatıların yerleştirilmesi ve topografyaya uyum hedeflenmiştir (Görsel 7).

\subsection{RekreasYol}

İncesu-Ürgüp eski karayolunun güneybatısında bulunan tarım alanları içerisindeki dağınık ve az yoğun konut alanlarını ele alan öğrenciler yol ile rekreatif kullanım ilişkilerini düzenleyen tasarımlar geliştirmiştir.

\subsection{Seyr-i İncesu ${ }^{18}$}

Külliye ve çevresindeki yapıların yüksek dik kayalıklar ortasında bulunması öğrencilerin bu alanı "iki balkon arasında seyredilmeye değer" bir bölge olarak tasarlamasına neden olmuştur. Yerleşmenin iki farklı noktadan seyredilebilir hale getirerek seyir terasları, kaya oyma mekânlar, çelik sistem konsollarla birlikte ulaşımın rampalarla organize edildiği kamusal mekân düzenlemeleri önerilmiştir (Görsel 8).

\subsection{Su - Rekreasyon ${ }^{19}$}

Yerleşmeyi güneybatı-kuzeydoğu istikametinde ikiye ayıran İncesu deresi ve çevresindeki bitki örtüsünün rekreasyonel nitelikleri vurgulanmış ve bir sınır elemanı olarak kullanılması eleştirilmiştir. Bu nedenle derenin iki yakasında geçirgenliği ve sürekliliği arttırmak ve kıyı kullanımlarını geliştirmek hedeflenmiştir. Ayrıca alan bütününde araç kullanımını kısıtlayıcı ve hatta yalnızca yaya erişimine açık tutulan yollar ile doğrudan suya temas edilmesi, yürünebilir bir kent parçası meydana getirilmesi istenmiştir (Görsel 9).

\footnotetext{
${ }^{18}$ Bu proje önerisi Tuğba Akkaya, Fatma Akbulut, Beyzanur Tuhan, Mücahit Talha Akçelep, Erdem Murakhas, Yashar Akhoon Nejad tarafindan geliştirilmiştir.

${ }^{19}$ Bu proje önerisi Hakan Albayrak, Seda Küçükkatırcı, Tugay Illhan, Dilan Gül Doğan, Ali Beşen tarafindan geliştirilmiştir.
} 

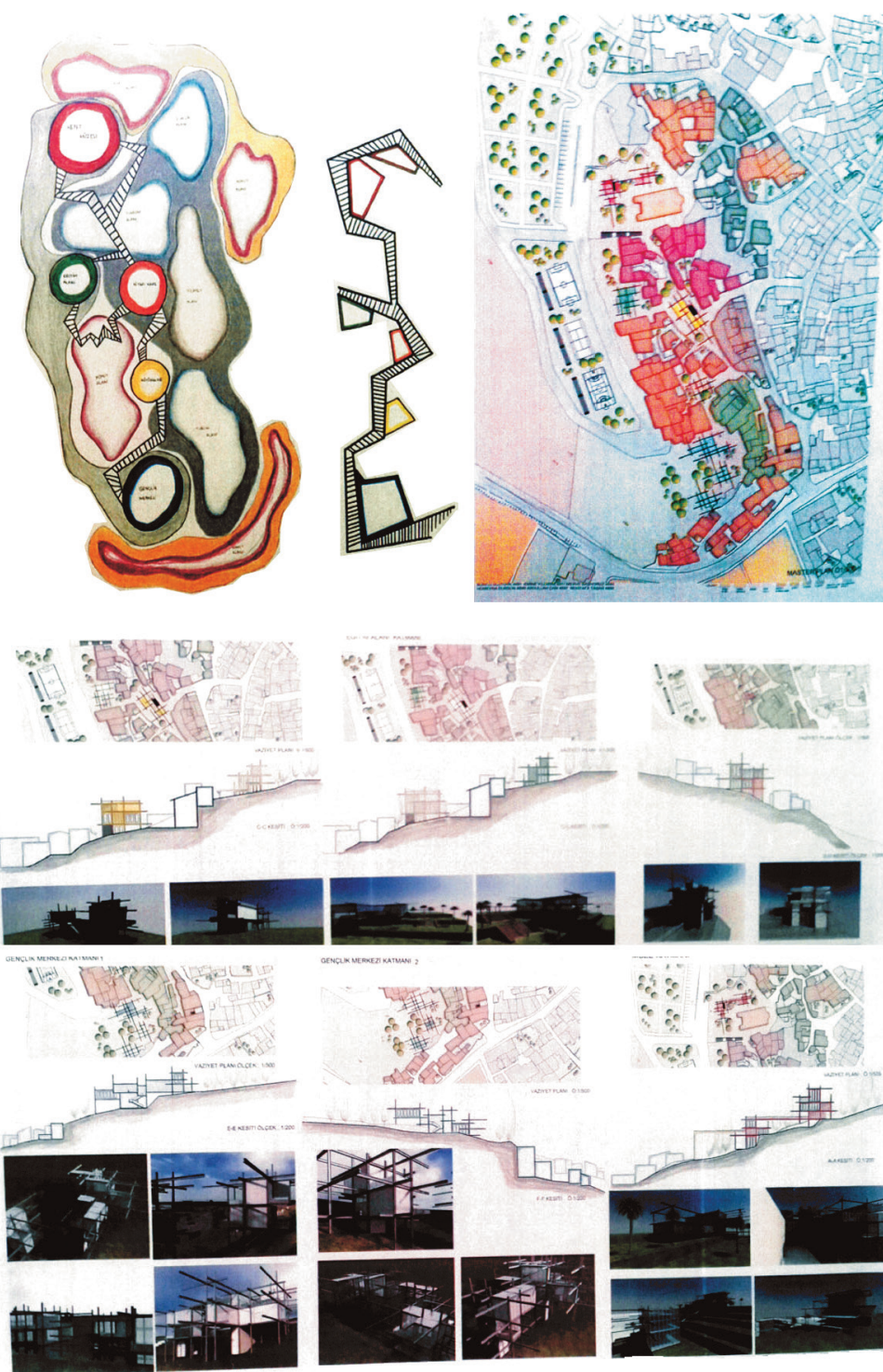

Görsel 7. Katman Proje Önerisinden Konsept Ve Kesit Detayları 

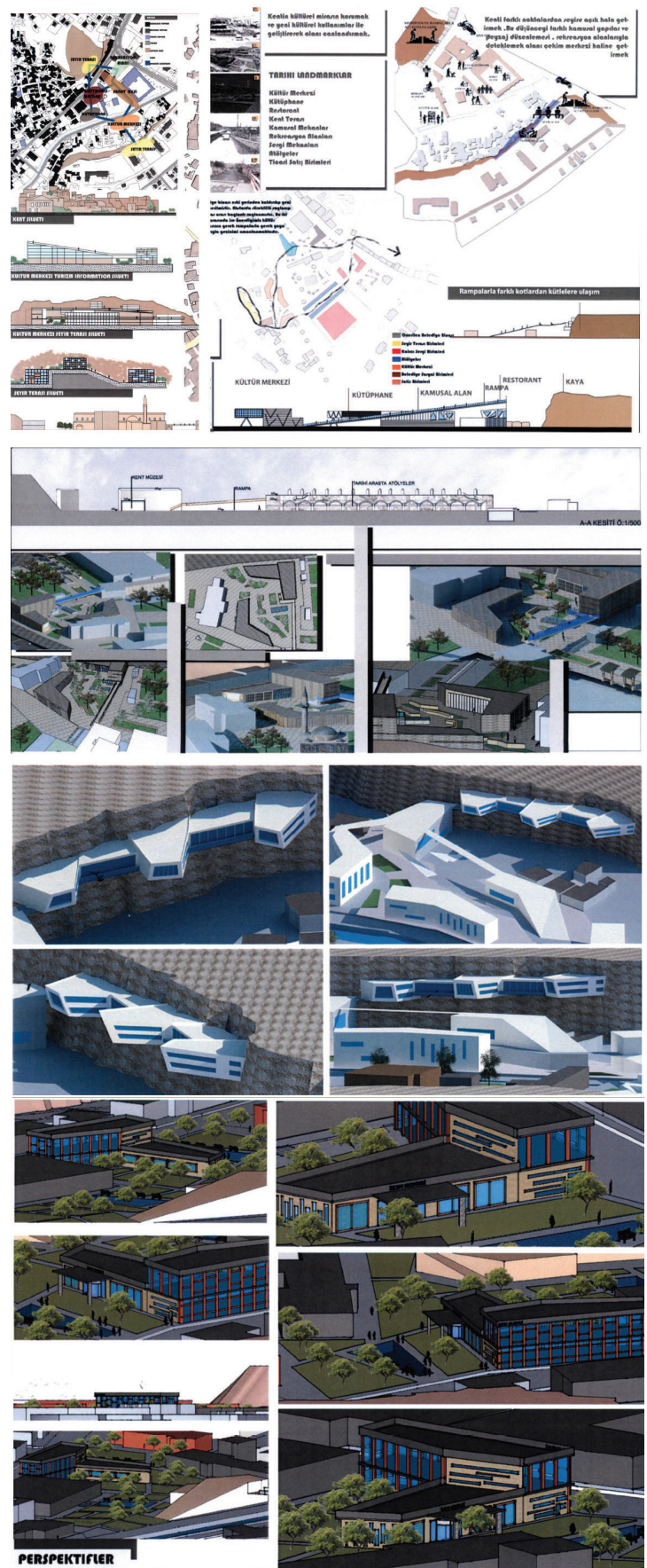

Görsel 8. Seyr-i Incesu Proje Önerisinden Kesit Ve 3D Modellemeler 

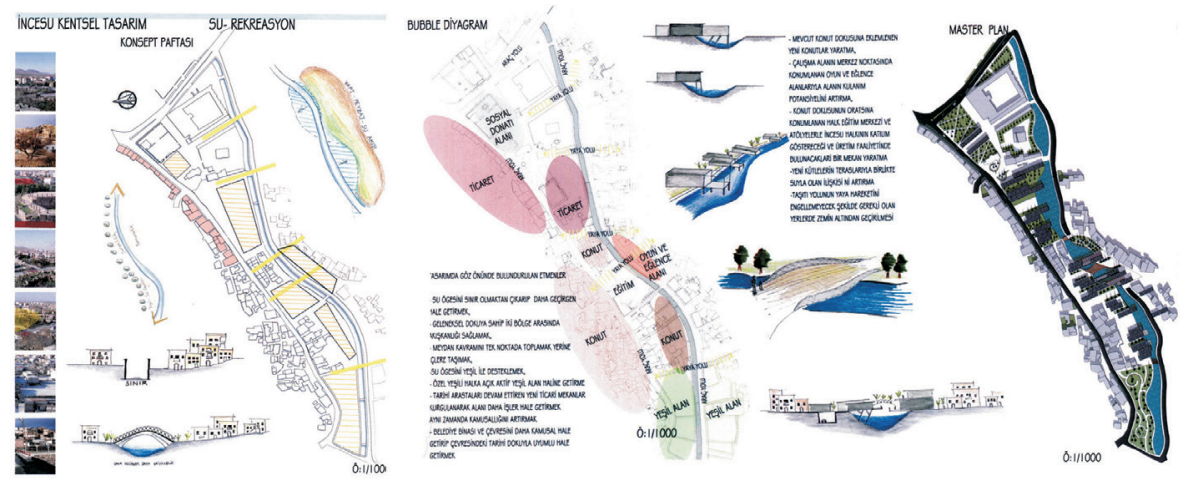

Görsel 9. Su-Rekreasyon Projesinden Detaylar

\section{Tartışma ve Sonuç}

Bu çalışmada kentsel tasarım eğitiminde karşılaşılan planlama ve kentsel tasarım arasındaki çelişkinin azaltılmasına ve eğitimi interdisipliner bir noktaya taşımaya yardımcı olmaya yönelik stüdyo eğitim süreci ve yöntemi açıklanmıştır. Ayrıca stüdyo süreci sonunda gelişme için katalizör olacak fırsatları saptayarak uygulanabilir ve gerçekleştirilebilir şemalar ortaya konulmuştur.

\section{1 İncesu Kentsel Tasarım Stüdyosundan Çıkarılan Dersler}

İncesu kenti iç bölgelerinin yenilenmesini içeren mekânsal planlama süreci mimari kalite ve mekân duygusunu yayan yeni bir çevrenin yaratılmasına odaklanmıştır. Bu bağlamda en belirleyici ve yönlendirici strateji kentsel manzara stratejisi olmuştur. Burada temel öngörü alanda dönüştürücü değişimin doğmasına yardımcı olmak ile mevcut nüfusun ihtiyaçlarını karşılarken yeni kent sakinlerinin alana gelişini çekici hale getirmektir. Bu sebeple ortaya çıkan mekânsal planların genel amacı gayrimenkulün bütüncül bir yeniden geliştirilmesini sağlarken aynı zamanda bölge içinde güçlü bir toplum duygusuna sahip olmayı ve bunu arttırmayı sağlamaktır. Mekânsal planların temel ilkeleri ise şu başlıklar altında toplanabilir:

- Şehri ikiye bölen İncesu nehri boyunca geliştirilen gayrimenkuller sayesinde kuzeydoğu(yeni kent dokusu) ile güneybatı(eski kent dokusu) arasındaki geçişi yani bağlantıyı güçlendirmek,

- Açık alanlar ağı yaratmak,

- Kent kimliğini oluşturmak ve güçlendirmek, 
- Iyi tasarlanmış caddeler ve yaya alanları meydana getirmek,

- Kamusal mekânlar ve donatı alanları oluşturmak.

İncesu kentsel tasarım stüdyo deneyimi verili bir tasarım alanı ve ihtiyaçlar programı olmaksızın öğrencilerin yaratıcı ve eleştirel düşünce yapısını sergilemektedir. Tasarım önerilerinin $1 / 3^{\prime} i$ konut dokusu ve yakın çevresi üzerine odaklanmasına karşın, bunun dışında alternatif gelişme stratejileri (bkz. Tablo 1) saptanmıştır. Büyük bir bölümü alan ve yer odaklı tasarım politikaları üzerinde durmasına karşın az da olsa belirli bir konuya (ev hanımları ve yetim çocuklar) yoğunlaşan tasarım politikaları sunulmuştur. Belirlenen problemler üzerinden ortaya çıkan şemalar ekonomik kalkınma amaçlarının yanı sıra iyi kentsel tasarım önerileri vermeyi amaçlamışır. Böylece iyi planlama ile iyi ve güzel tasarım bir arada sunulmuştur. On iki farklı konseptin en temel ortak noktası ise İncesu deresi ve su kıyısı kullanımlarıdır. Bu ortak duyum yerleşme adını su öğesinden almasına rağmen suya temas ve kıyııı yadsıyan biryapılaşmanın öğrenciler tarafından reddedildiğini göstermektedir. Benzer bir biçimde toplumdaki diğer sosyal grupların kadınlar ve çocuklar için eşitlik arayışı dile getirilmektedir.

\begin{tabular}{|c|c|c|c|c|}
\hline Kentsel Problemler & Konsept & $\begin{array}{l}\text { Alan } \\
\text { odaklı }\end{array}$ & $\begin{array}{c}\text { Yer } \\
\text { odaklı }\end{array}$ & $\begin{array}{l}\text { Konu } \\
\text { odaklı }\end{array}$ \\
\hline \multirow{2}{*}{ Dolaşım ve sokak ağ1 } & Bulvar & & & \\
\hline & RekreasYol & & & \\
\hline \multirow{2}{*}{$\begin{array}{l}\text { Kamusal kullanımlar, } \\
\text { mekânlar, landmarklar }\end{array}$} & Kadın & & & \\
\hline & Çocuk Esirgeme K. ve G. S. E. K. & & & \\
\hline \multirow{4}{*}{$\begin{array}{l}\text { Konut dokusu ve } \\
\text { yakın çevresi }\end{array}$} & Geçiş & & & \\
\hline & Katman & & & \\
\hline & Komşuluk ünitesi & & & \\
\hline & Su-Rekreasyon & & & \\
\hline \multirow{2}{*}{ Tarih, çevre ve insan } & İgnimbrite & & & \\
\hline & Seyr-i İncesu & & & \\
\hline \multirow{2}{*}{$\begin{array}{c}\text { Ticaret ve çalışma } \\
\text { alanları }\end{array}$} & Festival dé İncesu & & & \\
\hline & Organik Yaşam Durağı & & & \\
\hline
\end{tabular}

Tablo I. Kentsel Problem Alanı Ve Konsept Tasarımları

Açıkça görülmektedir ki, çağdaş kent için korumada modernizasyonun gereğini savunan; eski-yeni, geleneksel-modern çelişkilerinin bir arada uyumlu bir biçimde çözülebilmesini önceleyen stratejile ${ }^{20}$ her zaman ön plandadır. Araştırmada mimarlık öğrencilerine vizyoner yatırımcı, yani

\footnotetext{
${ }^{20}$ Bunlar sıklıkla topoğrafik eşik olarak kabul edilen yüksek eğimli kayalık alanlarını ilginç bir biçimde kamusal kullanımlara, mekânlara dönüştürmeyi amaçlamışlardır (bkz lgnimbrite ve Seyr-i Incesu).
} 
tasarım fikirlerini inşaat ve gayrimenkul piyasası ekseninde dengelemeyi isteyen bir rol kazandırılmıştır. Bu mülkleri yeni imar arsasına dönüştürmek yerine mevcut, fiziksel olarak tam gelişmiş ve son derece ilgi çekici bir ortamda kurulmuş yeni binalar inşa etmek olarak algılanmalıdır. $\mathrm{Bu}$ bağlamda adaptasyon ile uyumun pazarlanabilir bir gayrimenkul piyasası oluşturacağı ve böylece koruma müdahalelerinin finansmanını cesaretlendireceği söylenebilir.

\subsection{Kentsel Tasarım Tartışmalarına Katkı}

Kentsel tasarım hem işlevsel hem sanatsal, hem teknik, hem artistik, hem pratik, hem de pitoresk olmasını beklediğimiz bir yer yaratma sürecidir. Postmodern şehirciliğin cilaladığı kavramlardan biri olan kentsel tasarım parçacıl ve kent bütününü ele almaksızın gerçekleştirilmesi nedeniyle halen tartışma nedenidir. Her şeye rağmen, mekânsal planlama ile kentsel tasarım çok sayıda ölçek ve farklı mekân tanımları analiz etseler de birbirinden ayrılamaz bir içeriktedir. Dolayısıyla kentsel gelişme planlarının ileri sürdüğü tasarım politikaları, plan uygulamalarına karar verici bir statüye sahip olmakla birlikte kentsel tasarıma yol açıcı olmalıdır. Bir başka deyişle, iyi planlamanın başlıca hareket noktası, gerçekleşmesi güvence altına alınmış iyi tasarımlar olduğu gibi, iyi tasarımlar için koşulları yaratan planlama sistemini de etkili bir biçimde kullanmak gerekir. Sonuç olarak, görsel planlama ve pitoresk' in yer yaratma sürecinde yeniden inşa edilmesi süreci şehir planlamanın ortaya koyduğu stratejileri gerçekleştirme amacına uygun olarak yapılmalıdır. Aksi halde tablomsu bir şehirciliğin toplumsal bir şehircilik ile buluşması sağlanamayacaktır. 


\section{Kaynakça}

Aitchison, M. (Editör). (2010). Visual Planning and the Picturesque. Los Angeles: Getty Research Institute.

Commission for Architecture and the Built Environment, (CABE). (2000). By Design: Urban Design in the Planning System: Towards Better Practice. Rotherham: Her Majesty's Stationery Office.

Cullen, G. (196I). The Concise Townscape. New York: Van Nostrand Reinhold Co.

Giannopoulou, G. (20/4). “The Urban Designer After the Recession”, Urban Design, I32, 18-19.

Koralay, T., Zoroğlu, O. ve Kadığlu,Y. K. (2009). “Incesu İgnimbiritindeki (İncesu Kayseri) Fiamme Tiplerinin Kökeni: Petrografik ve Jeokimyasal Özellikleri”, S.Ü. Müh. Mim. Fak. Dergisi, 24(2), 45-68.

Rowe, C., ve Koetter, F. (1978). Collage City. Cambridge, Mass: MIT Press.

Russell, J. S. (2005). "Where Architecture is Urban Design”, Architectural Record, 193, (3), 62-66.

Sarı, M. ve Karababa, O. (2005). Dünden Bugüne Incesu. Kayseri: Netform Matbaacılık. Tozer, H.F. (I88I). Turkish Armenia and Eastern Asia Minor. Londra: Longmans.

\section{İnternet Kaynakları}

Internet: An Interview with Mathew Aitchison, https://getty.edu/research/publications/ pevsner/index.html I7 Mart 2016'da alınmıştır.

Internet: Hicks, J. (July, 20II). Painterly Urban Planning: Nikolaus Pevsner's "Visual Planning and the Picturesque". http://blogs.getty.edu/iris/painterly-urban-planningnikolaus-pevsners-visual-planning-and-the-picturesque/ adresinden I 7 Mart 2016'da alınmıştır.

Internet: Incesu haritası, https://www.google.com.tr/ maps/@38.626499I,35.I80044, I4z I3 Mart 20I6'da alınmıştır.

Internet: Smith, C. S. (2015, February 25th). Interview with Zaha Hadid, 'Zaha Hadid At The Royal Academy Of Arts'. Royal Academicians' Room, The Royal Academy of Arts, London http://alainelkanninterviews.com/zaha-hadid-ra/ adresinden 27 Mart 20I6'da alınmıştır. 
Internet: The Art of Creating and Shaping Cities and towns, http://www.urbandesign.org/ home.html 20 Mart 2016'da alınmıştır.

Internet: TÜiK. (2015). Adrese Dayalı Nüfus Kayıt Sistemi Sonuçları, https://biruni.tuik. gov.tr/medas/ 20 Mart 2016'da alınmıştır.

Internet: Türk Dil Kurumu. http://www.tdk.gov.tr/index.php?option=com_ gts\&arama = gts\&guid=TDK.GTS.590 I a l d84f7252.7660278I 27 Nisan 20 I 7'de alınmıştır. 